RESEARCH ARTICLE

\title{
Thin layer drying characteristics of fresh tea leaves*
}

\author{
W.S. Botheju ${ }^{* *}$, K.S.P. Amarathunge ${ }^{2}$ and I.S.B. Abeysinghe ${ }^{1}$ \\ ${ }^{1}$ Tea Research Institute, St. Coomb's Estate, Talawakelle. \\ ${ }^{2}$ Department of Agricultural Engineering, Faculty of Agriculture, University of Peradeniya, Peradeniya.
}

\begin{abstract}
Thin layer drying characteristics of fresh tea leaves were investigated to quantify the rate of moisture transfer of fresh tea leaves during the withering process within the temperature range of $20-35^{\circ} \mathrm{C}$, and a relative humidity range of $40-90 \%$ at $1.2 \pm 0.3 \mathrm{~m} / \mathrm{s}$ airflow rate. Five different mathematical models available in the literature were used with the drying data for fresh tea leaves using a constant climatic chamber. Results indicated that the Two-term model gives better predictions for moisture transfer than others. The desorption process of tea leaves occurred in falling rate period. The effective diffusivity of water in tea leaves varied from $3.3409-5.4669 \times 10^{-10} \mathrm{~m}^{2} / \mathrm{s}$ over the temperature range investigated with an activation energy of $1477.75 \mathrm{~kJ} / \mathrm{kg}$. The temperature dependence of diffusivity coefficient was described satisfactorily by a simple Arrhenius type relationship.
\end{abstract}

Keywords: Constant climatic chamber, desorption process, effective diffusivity, fresh tea leaves, tea withering, thin layer drying.

\section{INTRODUCTION}

Tea withering is an important unit operation in black tea processing. Fresh tea leaves received at the factory may contain $70-83 \%$ (w.b.) moisture depending on the climatic condition and the type of tea cultivar (Samaraweera, 1986). The moisture is reduced to about $55-60 \%$ (w.b.) during withering operation by careful handling of air temperature. A thick layer of leaf is loaded to a trough and an axial flow fan delivers $0.6-0.65 \mathrm{~m}^{3} / \mathrm{min} / \mathrm{kg}$ green leaves (GL) volume of air through the bed of leaves against the pressure of the $12-15 \mathrm{~mm}$ water gauge (Samaraweera, 1986). During the initial stage of withering, temperature of air is maintained around $32{ }^{\circ} \mathrm{C}$ if surface water is present in the leaves. At the later stage of withering, air temperature should be maintained well below $32{ }^{\circ} \mathrm{C}$ to preserve the quality of the leaves (Ranatunga et al., 1986).

Moisture transfer during withering influences the temperature changes of air due to the magnitude of latent heat of vaporization. To study the deep bed simulation of withering process, data on moisture transfer properties of fresh tea leaves at ambient conditions are needed. This study investigates moisture transfer characteristics of a thin layer of fresh tea leaves. Very little work has been done on thin layer drying characteristics of fresh tea leaves. Jayarathnam and Abdul Gaffer (1979) studied the desorption process of fresh tea leaves and reported that the constant rate period was observed for six different tea cultivars. However, the original source of data was not available.

Many studies have been conducted on thin layer drying characteristics of different food materials (Madamba et al., 1996; Panchariya et al., 2002) and different mathematical models have been used to describe thin layer drying data for different temperature ranges. These mathematical models can be categorized as theoretical, empirical and semi-empirical. Computational procedures of these models varied from simple to complex.

The objective of this study was to quantify the rate of moisture transfer of fresh tea leaves in the temperature range of withering operation carried out based on thin layer drying data. The experimental data were fitted into five different mathematical models which were available in the literature. Using the best-fit mathematical model, a relationship was developed between the drying coefficient of fresh tea leaves, air

\footnotetext{
* Corresponding author (wsbotheju@yahoo.com)

** Part of this paper was presented at the $2^{\text {nd }}$ Plantation Crop Research Symposium held from 16-17 October, 2008 at the Bandaranaika Memorial International Conference Hall (BMICH), Colombo.
} 
temperature and relative humidity (RH). The moisture diffusivity and activation energy of fresh tea leaves were also determined.

\section{METHODS AND MATERIALS}

Moisture desorption of leaves of tea cultivar TRI 2025 free from surface water was measured by a dynamic ventilator method. Air temperatures of 20, 25, 30 and $35^{\circ} \mathrm{C}$ and relative humidities of $40,50,60$ and $90 \%$ were achieved using a constant climatic chamber (model TMC 185/CRP-15, Teacraft, UK). These temperature and RH ranges covered the withering conditions in a tea factory. In practical situations, during dry periods in up country area, the RH drops well below 50\% (dry and wet bulb difference is about $12-14^{\circ} \mathrm{F}$ with dry bulb around $90^{\circ} \mathrm{F}$ ). On wet days it increases up to about $90 \%$. Therefore the two maximum possible extremes were considered in this study. The instrument is set at predetermined dry and wet bulb temperatures with an accuracy of $\pm 0.1{ }^{\circ} \mathrm{C}$ to obtain required $\mathrm{RH}$ (Table 1). The instrument was allowed to run empty for about $3 \mathrm{~h}$ to become stable, after setting dry and wet bulb temperatures.

As shown in Figure 1, $50 \mathrm{~g}$ leaf sample thinly spread on the tray was hung at the bottom of the electronic balance (Denver S-203) with an accuracy of $\pm 0.001 \mathrm{~g}$. A balance was connected to the computer via RS-232 serial cable to $\log$ the weights of leaf sample at constant time intervals. Readings were taken until the weight of sample reached a constant value. The dry weight of the resulting sample was determined by drying in an air oven at $103^{\circ} \mathrm{C}$ for $6 \mathrm{~h}$. The constant airflow rate of $1.2 \pm 0.3 \mathrm{~m} / \mathrm{s}$ was maintained in the chamber throughout the sorption period. The experiment was carried out in duplicate for the temperature and $\mathrm{RH}$ ranges studied.

Determination of drying coefficient in the desorption process: Moisture ratio (MR) versus drying time was fitted to five mathematical equations (Table 2). MR represents $\left(M-M_{e}\right) /\left(M_{o}-M_{e}\right)$; where $M_{o}$ and $M$ are denoted as moisture contents at the beginning and at a given time during withering, respectively. A non-linear regression programme (NLREG, Phillip H. Sherrod 6430 Annandale Cove, Brentwood, USA) was employed to fit experimental data into the five mathematical models.

The equilibrium moisture content $\left(\mathrm{M}_{\mathrm{e}}\right)$ of fresh tea leaves at a given temperature and $\mathrm{RH}$ were calculated using the modified Oswin equation (Botheju et al., 2008).
Table 1: Relative humidity of air corresponding to different dry and wet bulb temperatures

\begin{tabular}{ccc}
\hline \multicolumn{2}{c}{ Temperature $\left({ }^{\circ} \mathrm{C}\right)$} & $\begin{array}{l}\text { Relative } \\
\text { humidity }(\%)\end{array}$ \\
\hline Dry bulb & Wet bulb & 90 \\
20 & 18.9 & 40 \\
25 & 16.3 & 50 \\
25 & 17.9 & 60 \\
25 & 19.6 & 90 \\
25 & 23.8 & 50 \\
30 & 22.6 & 60 \\
30 & 23.9 & 90 \\
30 & 28.6 & 40 \\
35 & 23.9 & 60 \\
35 & 28.3 & 90 \\
35 & 33.5 & \\
\hline
\end{tabular}

Table 2: Mathematical models given by various authors for thin layer drying of materials

\begin{tabular}{lll}
\hline $\begin{array}{l}\text { Model } \\
\text { no. }\end{array}$ & Model name & Equation \\
\hline$(1)$ & Lewis & $M R=\exp (-k t)$ \\
$(2)$ & Henderson \& Pabis & $M R=a \cdot \exp (-k t)$ \\
$(3)$ & Logarithmic & $M R=a \cdot \exp (-k t)+c$ \\
$(4)$ & Page & $M R=\exp \left(-k t^{\mathrm{n}}\right)$ \\
$(5)$ & Two term model & $M R=a \cdot \exp \left(-k_{\mathrm{o}} t\right)+b \cdot \exp \left(-k_{1} t\right)$ \\
\hline
\end{tabular}

Where $k, k_{\mathrm{o}}$ and $k_{1}$ are drying coefficients; $a, b, c$ and $\mathrm{n}$ are constants and $t$ is time

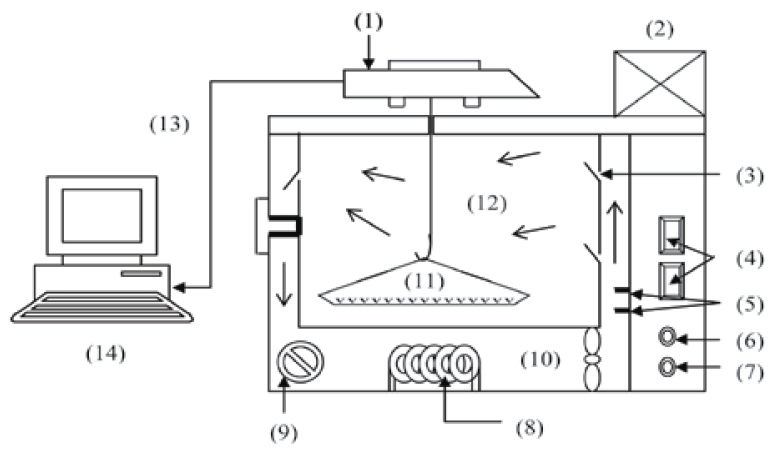
(1) Electronic balance
(8) Heating element
(2) Compressor
(9) Freezer unit
(3) Conditioned air inlet
(10) Fan
(4) Dry and wet bulb temperature display
(5) Dry and wet bulb temperature probes
(11) Thin layer of leaves
(6) Timer
(12) Chamber area
(7) Thermostat
(13) RS-232 serial cable
(14) Computer

Figure 1: Schematic diagram of the constant climatic chamber used for dynamic desorption of tea leaves 


$$
M_{e}=(55.4994-0.1272 T)\left[\frac{a_{w}}{1-a_{w}}\right]^{0.2275}
$$

where $\mathrm{T}$ is temperature $(\mathrm{K})$ and $a_{w}$ is water activity (decimal).

Analysis of data: Four statistical parameters viz. standard error of estimate (SEE) in equation (3), mean relative deviation percentage $(\mathrm{P})$ in equation (2), coefficient of determination $\left(\mathrm{R}^{2}\right)$ and the residual plots were used in the selection of the best-fit equation.

$$
\begin{aligned}
& P=\frac{100}{N} \sum \frac{\left|Y-Y^{\prime}\right|}{Y} \\
& \mathrm{SEE}=\sqrt{\frac{\sum\left(\mathrm{Y}-\mathrm{Y}^{\prime}\right)^{2}}{\mathrm{df}}}
\end{aligned}
$$

where $Y$ is the experimental data; $Y^{\prime}$ is the value predicted by the model; $N$ is the number of data points; if residual plot indicates a clear pattern, the model is not accepted (Weisberg, 1986).

An Arrhenius type relationship was developed between drying coefficient (k) of tea leaves and temperature and RH of air studied.

Calculation of effective diffusivity and activation energy: The drying characteristics of biological products in falling rate period can be described by using Fick's diffusion equation. The solution to this equation developed by Crank (1975) can be used for various regularly shaped bodies. The equation (4) given below can be applicable for food materials with slab geometry by assuming uniform initial moisture distribution.

$$
M R=\frac{8}{\pi^{2}} \sum_{n=0}^{\infty} \frac{1}{(2 n+1)^{2}} \exp \left(-\frac{(2 n+1)^{2} \pi^{2} D_{e f f} t}{4 L_{0}^{2}}\right)
$$

where $\mathrm{D}_{\text {eff }}$ is the effective diffusivity $\left(\mathrm{m}^{2} / \mathrm{s}\right)$ and $L_{0}$ is the half thickness of slab (m). For long drying period, equation (4) can be further simplified to only the first term of series (Tutuncu \& Labuza, 1996) and the logarithmic form can be given as follows (equation 5), which has similar form proposed by Henderson \& Pabis (1961).

$$
\ln M R=\ln \frac{8}{\pi^{2}}-\frac{\pi^{2} D_{e f f} t}{4 L_{0}^{2}}
$$

Diffusivities are determined by plotting experimental drying data in terms of $\ln M R$ versus drying time $(t)$ in equation (5). The slope of the straight line gives;

Slope $=-\frac{\pi^{2} D_{e f f}}{4 L_{0}^{2}}$

The temperature dependency of effective diffusivity is described by an Arrhenius type relationship (Madamba, et al., 1996; Akgun \& Doymaz, 2005) as follows;

$$
D_{\text {eff }}=D_{0} \exp \left(-\frac{E_{a}}{R T}\right)
$$

where $D_{0}$ is a constant equivalent to indefinitely high temperature and $E_{a}$ is the activation energy.

\section{RESULTS AND DISCUSSION}

TRI 2025, a common cultivar in tea estates in Sri Lanka, was selected to study thin layer drying properties of fresh tea leaves. Eleven combinations of temperature and relative humidity (Table 1) were studied using a constant climatic chamber. Initial moisture content of leaf samples varied between $75-80 \%$ (w.b.). Equilibrium moisture contents $\left(\mathrm{M}_{\mathrm{e}}\right)$ at selected temperature and $\mathrm{RH}$ were calculated using equation (1).

Moisture ratios (MR) verses drying time for tea leaves for eight combinations of temperature and $\mathrm{RH}$ are shown in Figure 2. It indicates that increasing air temperature or decreasing $\mathrm{RH}$ speeds up the drying/ withering process and thus shortens the withering time. Similar results were obtained for dehydration of apple (Vergara et al., 1997), drying of kiwifruit and apple pomace (Fenton \& Kennedy, 1998) etc.

The plots of drying rate verses drying time and the drying rate verses moisture content are shown in Figures 3 and 4 (six combinations were considered to avoid congestion) respectively. Figure 3 indicates that no constant rate period is observed in the withering process of tea leaves. Withering process takes place in a falling rate period and the rate of moisture removal is faster at the beginning than that at the end (Figure 4). This observation is in agreement with results on withering experiments carried out by Ghodake et al. (2006). Two falling rate periods could be observed in the tea withering process (Figure 4). The first falling rate period occurred when the moisture content of tea leaves was above $72 \%$ (w.b.) or $260 \%$ (d.b.), while the other was observed below $260 \%$.(d.b.). 


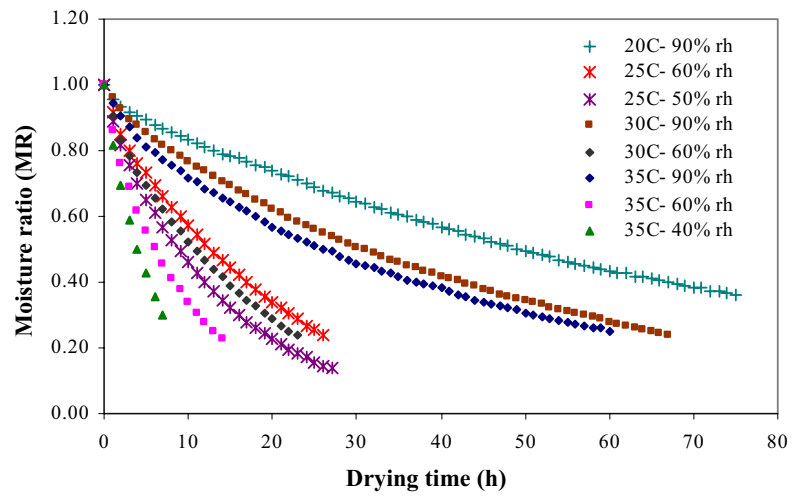

Figure 2: Thin layer drying curves of tea leaves at different temperatures and relative humidity levels

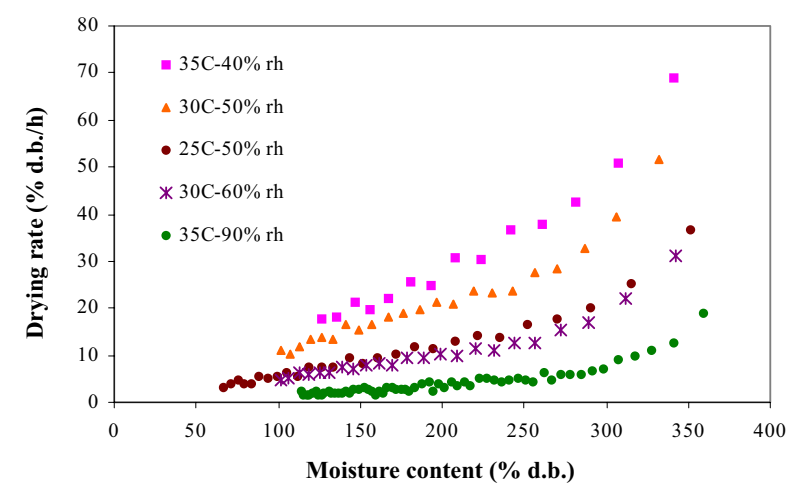

Figure 4: Drying rate versus moisture content of tea leaves at different temperatures and relative humidity levels

The colloidal and hyperbolic nature of food materials causes the water molecules to be tightly bound to the material (Mazza \& Le Maguer, 1980). Hence, the drying of almost all biological products takes place in the falling rate period. A constant rate period was observed before the falling rate in the study done by Jayaratnam and Abdul Gaffar (1979) for drying tea leaves of six different cultivars. Until the free surface water was removed from tea leaves, a constant rate period was observed in their drying curve.

Temple et al. (2000) reported that a single falling rate period was enough to describe the whole process of tea. However, using some industrial equipment a constant rate period could be observed due to limited evaporative capacity of the air. In such cases, constant rate period was a property of air supply rather than a drying property of the material.

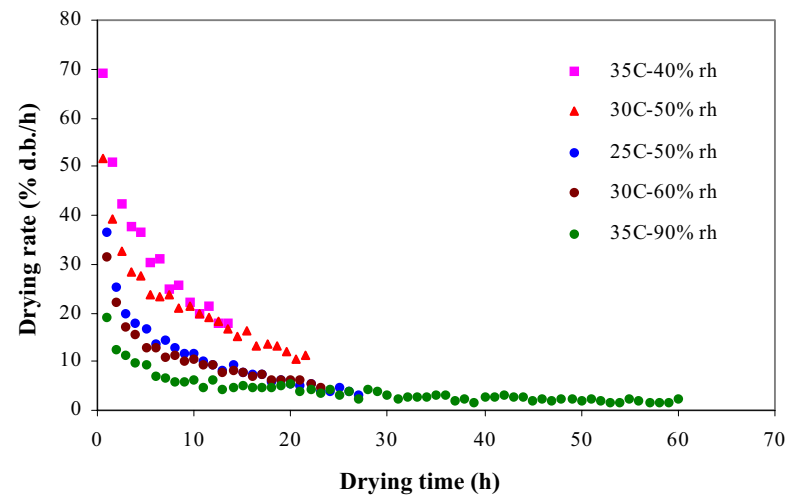

Figure 3: Drying rate versus drying time of tea leaves at different temperatures and relative humidity levels

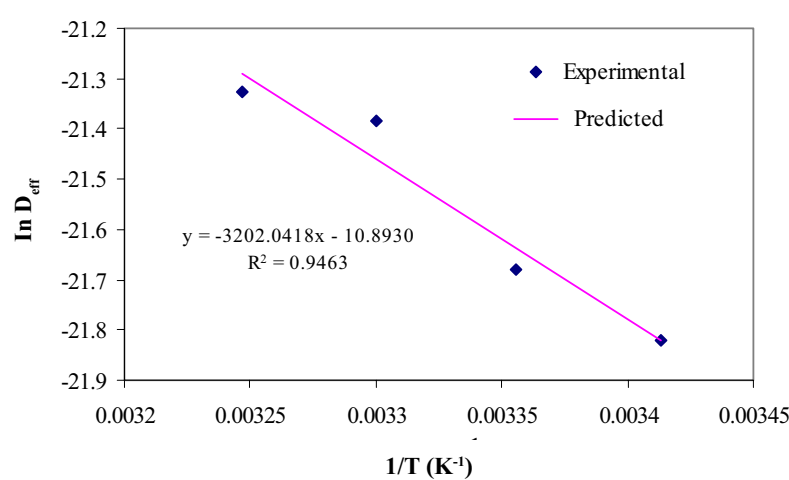

Figure 5: The relationship between $\ln \mathrm{D}_{\text {eff }}$ and $1 / \mathrm{T}$ of drying

\section{Modelling thin layer drying of tea leaves}

The curve of MR versus drying time (Figure 2) at different temperature and $\mathrm{RH}$ values was fitted to five mathematical models. Non-linear regression programme (NLREG) was performed to analyze the data. $\mathrm{R}^{2}$, SEE, $\mathrm{P}$ and residual plots were employed to evaluate the bestfit model and the calculated coefficients of each model are presented in Table 3.

$\mathrm{R}^{2}$ obtained for all five models were greater than 0.99. However, Page and Two-term models gave consistently higher $\mathrm{R}^{2}$ than the other three models. SEE and $\mathrm{P}$ calculated for Two-term model gave comparatively very low values than others. Moreover, when the residual plots for all model equations were compared, the Twoterm model characterized a random distribution for all treatments except the graph drawn for $35{ }^{\circ} \mathrm{C}$ and $60 \%$ RH. 
Table 3: Drying curve parameters for five models and the curve fitting criteria for each model for withering of tea leaves

\begin{tabular}{|c|c|c|c|c|c|c|c|c|c|c|}
\hline Model & $\mathrm{T}^{\circ} \mathrm{C}$ & $\mathrm{RH} \%$ & & & Constants & & $\mathrm{R}^{2}$ & SEE & $P$ & R/Plot \\
\hline \multirow{10}{*}{ Lewis } & 20 & 90 & $\mathrm{k}=0.0002$ & & & & 0.9987 & 0.0179 & 2.0593 & Pattern \\
\hline & 25 & 40 & $\mathrm{k}=0.0014$ & & & & 0.9981 & 0.0181 & 2.8486 & Pattern \\
\hline & 25 & 50 & $\mathrm{k}=0.0013$ & & & & 0.9984 & 0.0186 & 4.0216 & Pattern \\
\hline & 25 & 60 & $\mathrm{k}=0.0009$ & & & & 0.9974 & 0.0195 & 2.4583 & Pattern \\
\hline & 5 & 90 & $\mathrm{k}=0.0003$ & & & & 0.9979 & 0.0151 & 2.0526 & Pattern \\
\hline & 30 & 60 & $\mathrm{k}=0.0011$ & & & & 0.9970 & 0.0207 & 3.1426 & Pattern \\
\hline & 30 & 90 & $\mathrm{k}=0.0004$ & & & & 0.9987 & 0.0196 & 3.3193 & Pattern \\
\hline & 35 & 40 & $\mathrm{k}=0.0029$ & & & & 0.9988 & 0.0120 & 1.5264 & Pattern \\
\hline & 35 & 60 & $\mathrm{k}=0.0019$ & & & & 0.9982 & 0.0196 & 3.5677 & Pattern \\
\hline & 35 & 90 & $\mathrm{k}=0.0004$ & & & & 0.9955 & 0.0345 & 6.2345 & Pattern \\
\hline \multirow{10}{*}{$\begin{array}{l}\text { Hen \& } \\
\text { Pabis }\end{array}$} & 20 & 90 & $\mathrm{k}=0.0002$ & & $\mathrm{a}=0.9576$ & & 0.9986 & 0.0057 & 0.3842 & Random \\
\hline & 25 & 40 & $\mathrm{k}=0.0013$ & & $a=0.9608$ & & 0.9976 & 0.0103 & 1.2525 & Pattern \\
\hline & 25 & 50 & $\mathrm{k}=0.0012$ & & $\mathrm{a}=0.9555$ & & 0.9980 & 0.0106 & 1.4896 & Pattern \\
\hline & 25 & 60 & $\mathrm{k}=0.0009$ & & $\mathrm{a}=0.9582$ & & 0.9974 & 0.0112 & 1.1769 & Pattern \\
\hline & 25 & 90 & $\mathrm{k}=0.0003$ & & $a=0.9683$ & & 0.9978 & 0.0086 & 1.2254 & Random \\
\hline & 30 & 60 & $\mathrm{k}=0.0010$ & & $\mathrm{a}=0.9530$ & & 0.9965 & 0.0120 & 1.0755 & Random \\
\hline & 30 & 90 & $\mathrm{k}=0.0003$ & & $\mathrm{a}=0.9544$ & & 0.9982 & 0.0086 & 1.1713 & Random \\
\hline & 35 & 40 & $\mathrm{k}=0.0028$ & & $a=0.9791$ & & 0.9987 & 0.0081 & 0.8630 & Random \\
\hline & 35 & 60 & $\mathrm{k}=0.0018$ & & $\mathrm{a}=0.9581$ & & 0.9975 & 0.0114 & 1.6978 & Pattern \\
\hline & 35 & 90 & $\mathrm{k}=0.0004$ & & $\mathrm{a}=0.9195$ & & 0.9932 & 0.0166 & 2.5324 & Pattern \\
\hline \multirow{10}{*}{ Logarit } & 20 & 90 & $\mathrm{k}=0.0002$ & & $\mathrm{a}=0.9281$ & $\mathrm{c}=0.0321$ & 0.9987 & 0.0056 & 0.3929 & Random \\
\hline & 25 & 40 & $\mathrm{k}=0.0015$ & & $a=0.8779$ & $\mathrm{c}=0.0959$ & 0.9986 & 0.0076 & 0.9813 & Random \\
\hline & 25 & 50 & $\mathrm{k}=0.0013$ & & $\mathrm{a}=0.9300$ & $\mathrm{c}=0.0350$ & 0.9984 & 0.0096 & 1.6188 & Pattern \\
\hline & 25 & 60 & $\mathrm{k}=0.0009$ & & $\mathrm{a}=0.9397$ & $\mathrm{c}=0.0214$ & 0.9984 & 0.0114 & 1.3594 & Pattern \\
\hline & 25 & 90 & $\mathrm{k}=0.0003$ & & $\mathrm{a}=0.9134$ & $c=0.0609$ & 0.9980 & 0.0082 & 1.0813 & Random \\
\hline & 30 & 60 & $\mathrm{k}=0.0012$ & & $\mathrm{a}=0.8945$ & $\mathrm{c}=0.0694$ & 0.9972 & 0.0112 & 1.5851 & Random \\
\hline & 30 & 90 & $\mathrm{k}=0.0004$ & & $\mathrm{a}=0.8948$ & $\mathrm{c}=0.0719$ & 0.9989 & 0.0068 & 0.9857 & Random \\
\hline & 35 & 40 & $\mathrm{k}=0.0031$ & & $\mathrm{a}=0.9350$ & $\mathrm{c}=0.0491$ & 0.9989 & 0.0077 & 1.0286 & Pattern \\
\hline & 35 & 60 & $\mathrm{k}=0.0021$ & & $\mathrm{a}=0.8885$ & $\mathrm{c}=0.0857$ & 0.9988 & 0.0078 & 1.2036 & Pattern \\
\hline & 35 & 90 & $\mathrm{k}=0.0005$ & & $\mathrm{a}=0.8058$ & $\mathrm{c}=0.1422$ & 0.9973 & 0.0104 & 1.3871 & Pattern \\
\hline \multirow{10}{*}{ Page } & 20 & 90 & $\mathrm{k}=0.0006$ & & $\mathrm{n}=0.8782$ & & 0.9975 & 0.0086 & 1.0656 & Pattern \\
\hline & 25 & 40 & $\mathrm{k}=0.0029$ & & $\mathrm{n}=0.8783$ & & 0.9994 & 0.0043 & 0.7164 & Random \\
\hline & 25 & 50 & $\mathrm{k}=0.0026$ & & $\mathrm{n}=0.8940$ & & 0.9991 & 0.0069 & 1.7905 & Pattern \\
\hline & 25 & 60 & $\mathrm{k}=0.0020$ & & $\mathrm{n}=0.8895$ & & 0.9976 & 0.0111 & 1.9684 & Pattern \\
\hline & 25 & 90 & $\mathrm{k}=0.0006$ & & $\mathrm{n}=0.9045$ & & 0.9979 & 0.0084 & 1.1221 & Random \\
\hline & 30 & 60 & $\mathrm{k}=0.0026$ & & $\mathrm{n}=0.8657$ & & 0.9985 & 0.0086 & 1.7201 & Random \\
\hline & 30 & 90 & $\mathrm{k}=0.0009$ & & $\mathrm{n}=0.8794$ & & 0.9994 & 0.0057 & 0.9340 & Random \\
\hline & 35 & 40 & $\mathrm{k}=0.0044$ & & $\mathrm{n}=0.9259$ & & 0.9994 & 0.0057 & 0.9420 & Random \\
\hline & 35 & 60 & $\mathrm{k}=0.0039$ & & $\mathrm{n}=0.8782$ & & 0.9998 & 0.0035 & 0.7031 & Random \\
\hline & 35 & 90 & $\mathrm{k}=0.0021$ & & $\mathrm{n}=0.7887$ & & 0.9994 & 0.0051 & 0.8962 & Random \\
\hline \multirow{10}{*}{$\begin{array}{l}\text { Two } \\
\text { term }\end{array}$} & 20 & 90 & $\mathrm{k}_{\mathrm{o}}=0.0002$ & $\mathrm{k}_{1}=0.0002$ & $\mathrm{a}=0.9788$ & $\mathrm{~b}=0.0788$ & 0.9986 & 0.0058 & 0.3842 & Random \\
\hline & 25 & 40 & $\mathrm{k}_{\mathrm{o}}=0.0012$ & $\mathrm{k}_{1}=0.0168$ & $\mathrm{a}=0.9327$ & $\mathrm{~b}=0.0673$ & 0.9998 & 0.0023 & 0.3574 & Random \\
\hline & 25 & 50 & $\mathrm{k}_{\mathrm{o}}=0.0012$ & $\mathrm{k}_{1}=0.0195$ & $\mathrm{a}=0.9279$ & $b=0.0726$ & 0.9999 & 0.0017 & 0.4175 & Random \\
\hline & 25 & 60 & $\mathrm{k}_{\mathrm{o}}=0.0008$ & $\mathrm{k}_{1}=0.0248$ & $\mathrm{a}=0.9403$ & $\mathrm{~b}=0.0601$ & 0.9994 & 0.0057 & 1.0517 & Random \\
\hline & 25 & 90 & $\mathrm{k}_{\mathrm{o}}=0.0003$ & $\mathrm{k}_{1}=0.0073$ & $\mathrm{a}=0.9587$ & $\mathrm{~b}=0.0418$ & 0.9986 & 0.0068 & 0.9960 & Random \\
\hline & 30 & 60 & $\mathrm{k}_{\mathrm{o}}=0.0010$ & $\mathrm{k}_{1}=0.0184$ & $\mathrm{a}=0.9245$ & $\mathrm{~b}=0.0759$ & 0.9997 & 0.0037 & 0.7124 & Random \\
\hline & 30 & 90 & $\mathrm{k}_{\mathrm{o}}=0.0003$ & $\mathrm{k}_{1}=0.0045$ & $a=0.9300$ & $\mathrm{~b}=0.0662$ & 0.9998 & 0.0027 & 0.5085 & Random \\
\hline & 35 & 40 & $\mathrm{k}_{\mathrm{o}}=0.0027$ & $\mathrm{k}_{1}=0.0594$ & $\mathrm{a}=0.9630$ & $\mathrm{~b}=0.0371$ & 0.9998 & 0.0032 & 0.5189 & Random \\
\hline & 35 & 60 & $\mathrm{k}_{\mathrm{o}}=0.0018$ & $\mathrm{k}_{1}=0.0018$ & $\mathrm{a}=0.9791$ & $\mathrm{~b}=0.0791$ & 0.9975 & 0.0119 & 1.6978 & Pattern \\
\hline & 35 & 90 & $\mathrm{k}_{\mathrm{o}}=0.0003$ & $\mathrm{k}_{1}=0.0041$ & $\mathrm{a}=0.8652$ & $\mathrm{~b}=0.1274$ & 0.9997 & 0.0037 & 0.6169 & Random \\
\hline
\end{tabular}


When comparing all statistical parameters Two-term model fitted well with the experimental data than the other four models. Therefore, Two-term model was selected as the best-fit mathematical equation to explain the experimental desorption data of fresh tea leaves.

Regression analysis was used to find the relationship between withering temperature, $\mathrm{RH}$ as against drying coefficients $k_{o}$ and $k_{1}\left(\mathrm{~min}^{-1}\right)$ of Two-term model. Thus the drying coefficients $k_{o}, k_{1}$ against temperature and $\mathrm{RH}$ can be expressed as an Arrhenius type relationship. A similar type of relationship has been developed for deep bed rice drying (Murata et al., 1996).

$k_{o}=\exp \left(\frac{l_{1} h^{3}+l_{2} h^{2}+l_{3} h+l_{4}}{T}+l_{5}\right)$

$l_{1}=17348.8243 \quad \mathrm{R}^{2}=0.981 \quad \mathrm{SEE}=0.1422 \times 10^{-3}$

$l_{2}=-34192.6303$

$l_{3}=20236.1163$

$l_{4}=-10548.7579$

$l_{5}=16.2159$

$k_{1}=\exp \left(\frac{m_{1} h^{3}+m_{2} h^{2}+m_{3} h+m_{4}}{T}+m_{5}\right)$

$m_{1}=3088.9199 \quad \mathrm{R}^{2}=0.990 \quad \mathrm{SEE}=0.2234 \times 10^{-2}$

$m_{2}=-7028.6863$

$m_{3}=3744.3320$

$m_{4}=-8633.3896$

$m_{5}=23.3388$

Table 4: Effective diffusivities of fresh tea leaves at different temperatures

\begin{tabular}{cc}
\hline Temperature $\left({ }^{\circ} \mathrm{C}\right)$ & $\begin{array}{c}\text { Average effective } \\
\text { diffusivities }\left(\times 10^{-10} \mathrm{~m}^{2} / \mathrm{s}\right)\end{array}$ \\
\hline 20 & 3.3409 \\
25 & 3.8471 \\
30 & 5.1632 \\
35 & 5.4669 \\
\hline
\end{tabular}

where $h$ and $T$ are relative humidity (decimal) and temperature (Kelvin) respectively.

The constants ' $a$ ' and ' $b$ ' did not show any significant variation for the range of temperature and RH (Table 3) studied. Therefore, the average values of ' $a$ ' and ' $b$ ' were considered. The final Two-term model can be expressed as follows.

$$
M R=0.9462 \exp \left(-k_{o} t\right)+0.0691 \exp \left(-k_{1} t\right)
$$

\section{Determination of effective diffusivities and activation energy}

The results have shown that internal mass transfer resistance controls the drying time due to presence of the falling rate period. The values of effective diffusivity $\left(\mathrm{D}_{\text {eff }}\right)$ at different temperatures could be obtained by using equations (5) and (6). The average values of effective diffusivities of tea leaves in the desorption process at $20-35{ }^{\circ} \mathrm{C}$ varied in the range of $3.3409-5.4669 \times 10^{-10} \mathrm{~m}^{2} / \mathrm{s}$ (Table 4$)$. The effective diffusivity increases exponentially with the increase of air temperature. These results are in agreement with the previous investigations within the general range of $10^{-9}$ to $10^{-11} \mathrm{~m}^{2} / \mathrm{s}$ for food materials (Botheju et al., 2008).

A linear relationship was derived from the equation (7) and natural logarithmic of $\mathrm{D}_{\text {eff }}$ was plotted as against $1 / \mathrm{T}$ (Figure 5). The energy of activation $\left(\mathrm{E}_{\mathrm{a}}\right)$ for water diffusion of tea leaves calculated from the slope of the straight line was found to be $1477.75 \mathrm{~kJ} / \mathrm{kg}$, which was in the range of drying onion $1200 \mathrm{~kJ} / \mathrm{kg}$ (Mazza \& Le Maguer, 1980), rice $1183 \mathrm{~kJ} / \mathrm{kg}$ (Pinaga et al., 1984) and paprika $2036 \mathrm{~kJ} / \mathrm{kg}$ (Carbonell et al., 1986). The activation energy barrier must be overcome to activate moisture diffusion. To increase drying rates by increasing moisture diffusion, use of high temperatures would be beneficial but it is advisable to use optimum temperatures (Ranatunga et al., 1986; Keegal, 1965) to maintain the quality of tea leaves during withering.

\section{References}

1. Akgun N.A. \& Doymaz I. (2005). Modeling of olive cake thin layer drying process. Journal of Food Engineering 68(4): $455-461$.

2. Botheju W.S., Amaratunge K.S.P. \& Abeysinghe I.S.B. (2008). Modeling desorption isotherms of fresh tea leaves. Proceedings of the National Symposium, 23-24 October, Faculty of Agriculture, University of Ruhuna, pp. 136.

3. Carbonell J.V., Pinaga F., Yusa V. \& Pena J.L. (1986). Dehydration of paprika and kinetics of colour degradation. Journal of Food Technology 5(3): 179 - 193.

4. Crank J. (1975). The Mathematics of Diffusion. Oxford University Press, London, UK.

5. Fenton G.A. \& Kennedy M.J. (1998). Rapid dry weight determination of kiwifruit pomace and apple pomace using an infrared drying technique. New Zealand Journal of Crop and Horticulture Science 26(1): 35-38.

6. Ghodake H.M., Goswami T.K. \& Chakraverty A. (2006). Mathematical modeling of withering characteristics of tea leaves. Drying Technology 24(2): 159-164.

7. Jayaratnam S. \& Abdul Gaffar N.M. (1979). Equilibrium moisture content and withering. Tea Quarterly $48(1 \& 2)$ : 21-25. 
8. Keegal E.L. (1965). Withering. Tea Manufacture in Ceylon. Monographs on Tea Production in Ceylon (eds. E.L Keegal), $2^{\text {nd }}$ edition, pp. 28-41. Tea Research Institute of Sri Lanka, St. Coombs Estate, Talawakelle.

9. Madamba P.S., Driscoll R.H. \& Buckle K.A. (1996). The thin-layer drying characteristics of garlic slices. Journal of Food Engineering 29(1): 75-87.

10. Mazza G. \& Le Maguer M. (1980). Dehydration of onions: some theoretical and practical considerations. Journal of Food Technology 15(1): 191-194.

11. Murata S., Amaratunga K.S.P., Tanaka F., Shibuya K. \& Koide S. (1996). Simulation of moisture adsorption by polished rice in deep-bed. Food Science \& Technology International Tokyo 2(2): 86-91.

12. Pinaga F., Carbonell J.V., Pena J.L. \& Miguel J.J. (1984). Experimental simulation of solar drying of garlic using an absorbent energy storage bed. Journal of Food Technology 3(3): 187 - 203.

13. Panchariya P.C., Popovic D. \& Sharma A.L. (2002). Modeling of black tea drying process. Journal of Food Engineering 52(4): 349-357.
14. Ranatunga D.B.J., Boęrje K. \& Senanayake G. (1986). Energy needs of tea manufacture. Transactions 1(1): 30-51.

15. Samaraweera D.S.A. (1986). Technology of tea processing. Handbook on Tea (eds. P. Sivapalan, S. Kulasegaram \& A. Kathiravetpillai), pp. 158-207. Tea Resesearch Institute of Sri Lanka, St. Coombs Estate, Talawakelle.

16. Temple S.J., Tambala S.T. \& van Boxtel A.J.B. (2000). Monitoring and control of fluid-bed drying of tea. Control Engineering Practice 8(1): 165-173.

17. Tutuncu M.A. \& Labuza T.P. (1996). Effect of geometry on the effective moisture transfer diffusion coefficient. Journal of Food Engineering 30(4): 433-447.

18. Vergara F., Amezaga E., Barcenas M.E. \& Welti J. (1997). Analysis of the drying processes of osmotically dehydrated apple using the characteristic curve model. Drying Technology 15(3\&4): 949-963.

19. Weisberg S. (1986). Applied Linear Regression, $2^{\text {nd }}$ edition, pp. 132. John Willey \& Sons, New York, USA. 